\title{
A construção social do corpo: como a perseguição do ideal do belo influenciou as concepções de saúde na sociedade brasileira contemporânea
}

\author{
Rômulo Mágnus de Castro Sena* \\ Ellany Gurgel Cosme do Nascimento** \\ Patrícia Rakel de Castro Sena*** \\ Lia Maristela da Silva Jacob**** \\ Eulália Maria Chaves Maia*****
}

\begin{abstract}
Resumo
A presente revisão narrativa objetivou resgatar a construção histórica e social do corpo, evidenciando nesse processo o ideal de beleza, perseguido ao longo dos anos por diversas culturas e suas repercussões sobre a concepção de saúde produzida na sociedade brasileira contemporânea. Para tanto o corpus discursivo foi estruturado em quatro tópicos, a saber: Descobrindo a Beleza: a instituição de uma imagem do corpo ideal na antiguidade clássica; Encobrindo a Beleza: o corpo como lugar de expiação e especulação científica; Reinventando a Beleza: como a mídia pauta novas exigências de construção da imagem corporal; e, A satisfação com a imagem corporal como preditor de saúde. Percebe-se que embora a beleza tenha sido uma das grandes ocupações e preocupações do homem, não se constata esforços no intento de defini-la, aparecendo como um aspecto da imagem corporal, com relativos atributos divinais, já que os indivíduos são incentivados a persegui-la e atingi-la.
\end{abstract}

Palavras-chave: imagem corporal, beleza, história da medicina, sociologia médica

The social construction of body as the pursuit of the ideal of beauty has influenced health concepts in contemporary Brazilian society

\begin{abstract}
The present narrative review aimed to rescue the historical and social construction of the body, evidencing in this process the ideal of beauty pursued over the years by diverse cultures and their repercussions on the conception of health produced in contemporary Brazilian society. For this purpose the discursive corpus was structured in four topics, namely: Discovering Beauty: the institution of an ideal body image in classical antiquity; Covering Beauty: the body as a place of atonement and scientific speculation; Reinventing Beauty: how the media guides new demands on body image building; and, Satisfaction with body image as a health predictor. It is perceived that although beauty was one of the great occupations and preoccupations of man, no effort is made to define it, appearing as an aspect of body image, with relative divine attributes, since individuals are encouraged to pursue and hit it.

Keywords: body image, beauty, history of medicine, medical sociology
\end{abstract}

* Enfermeiro, Mestre em Psicologia pela UFRN e Doutorando em Ciências Médicas, área de concentração Saúde Mental, na UNICAMP.

** Enfermeira, Doutora em Ciências da Saúde pela UFRN. Docente dos cursos de enfermagem e Pós-Graduação em saúde e sociedade da UERN.

*** Jornalista, Doutora em Comunicação pela UFPE e professora adjunta do Departamento de Comunicação Social da UFMA.

**** Enfermeira, Mestra em Saúde Coletiva pela UNIFOR, Doutoranda em Ciências da Saúde na UNICAMP.

***** Psicóloga, Mestra em Psicologia Clínica pela PUCRS e Doutora pela USP. Professora titular na UFRN e bolsista produtividade CNPq. 


\section{Introdução}

O corpo humano tem se evidenciado como objeto de estudos dos mais diferentes campos do conhecimento, sobretudo, a partir da emergência do discurso da interdisciplinaridade no meio profissional e científico. Certamente que o afinco desse interesse se deve às transformações sofridas ao longo da construção da sociedade ocidental; haja vista o fato de até o século XVIII a igreja deter o monopólio do pensamento. O corpo era espaço de expiação e por isso deveria ser reprimido; já no século XIX ele é apropriado pelo Capitalismo e assim por diante. Logo, percebe-se que as concepções sobre o corpo são mutáveis com o decorrer do tempo e são influenciadas por questões políticas, econômicas, sociais e religiosas das classes dominantes de cada período (Cassimiro, Galdino \& Sá, 2012)

Atualmente, a busca pelo corpo perfeito tem sido largamente difundida pelos meios de comunicação, constituindo-se como uma das principais ocupações e preocupações do homem, cuja confirmação se percebe pelos índices cada vez maiores de cirurgias plásticas, estéticas e reparadoras. Por trás de um discurso construído sobre a saúde se esconde a faceta das variáveis e expressões de poder da forma, tanto daqueles que podem pagar para exibir a "perfeição" de seus corpos, como para aqueles que manipulam a metamorfose (cirurgiões plásticos) para atingi-la.

Assim sendo, o presente artigo trata-se de uma revisão narrativa (Rother, 2007) que, a partir de uma ampla investigação em fontes de publicação científica, objetivou descrever e discutir o "estado da arte" sobre a construção histórica e social do corpo, evidenciando, nesse processo, o ideal do belo, perseguido ao longo dos anos por diversas culturas e suas repercussões sobre a concepção de saúde produzida na sociedade contemporânea brasileira.

\section{Desenvolvimento}

\section{Descobrindo a Beleza: a instituição de uma imagem do corpo ideal na antiguidade clássica}

A produção de uma imagem de corpo ideal na Grécia, ainda hoje atraente e considerada referência, mostra o potencial de veiculação cultural dos ideais estéticos; essa imagem idealizada correspondia ao próprio conceito de cidadão para os gregos, os quais deveriam persegui-la por meio de exercícios e meditação. O corpo, naquele contexto, era visto como um elemento tanto de glorificação quanto de interesse para o Estado (Barbosa, Matos \& Costa, 2011).
Apesar de assuntos como Política e Ética serem considerados de maior relevância pelos filósofos, o corpo também era um tema bastante discutido na Grécia Antiga. Para Sócrates, que tinha uma visão do homem integral, tanto o corpo quanto a alma eram importantes no processo de interação do indivíduo com o mundo; já Platão defendia a existência de um dualismo humano, no qual o corpo constituía-se como uma prisão para a alma. Aristóteles, por sua vez, fazendo um retorno a Sócrates, defendia o envolvimento contínuo dos dois elementos para a realização das ações humanas (Cassimiro, Galdino \& Sá, 2012).

A Nudez é um aspecto bastante marcante nas esculturas do Parthenon, símbolo da jovialidade e perfeição, em que cada cidadão era livre para atingir o corpo perfeito, geralmente "esculpido" e modelado nos ginásios para serem expostos durante os jogos olímpicos. O nu representava, ainda, a saúde, a expressão de beleza de um corpo saudável e bem proporcionado em uma civilização sem nenhum pudor físico. Para os gregos o corpo materializava a criatividade dos deuses, por isso ele deveria ser exibido, condicionado, treinado, perfumado e adorado; despertando a admiração e a inveja dos demais mortais (Barbosa, Matos \& Costa, 2011).

O nu é tão constante na cultura grega que aparece em situações tidas talvez como inusitadas, a exemplo da guerra, cujo ambiente bélico não parece representar um lugar antropológico de sua manifestação, haja vista ser um combate de morte, no qual a defesa do corpo representa a própria sobrevivência, logo, apresentar um guerreiro sem proteção exporia suas vulnerabilidades ao inimigo (Rodrigues, 2011). Entretanto, essa exposição não se tratava apenas de narcisismo, mas representava o corpo como próprio instrumento de combate; a luta era, pois, uma constante na natureza, e as próprias provas das olimpíadas eram uma oportunidade dos indivíduos se mostrarem merecedores do dom da vida dado pelos deuses (Barbosa, Matos \& Costa, 2011).

Nesse cenário, o corpo das mulheres não ganha a mesma evidência que o dos homens, porque como a função social delas era a reprodução e o respeito ao pai e ao marido, não lhes era permitido tal cuidado com o corpo (Deus, Martins \& Santiago, 2013). No entanto, há que se considerar que as mulheres espartanas constituíam uma exceção, pois como é sabido, elas eram dotadas de um prestígio social que lhes autorizava o discurso de aconselhamento frente às decisões do conselho, eram conhecidas pela bravura e altivez com que conseguiam conciliar as tarefas do lar com a vida política e social, 
por isso, a essas figuras eram facultados os treinos de ginástica e cuidados com o corpo.

Esse cuidar de si foi o precursor do individualismo nas civilizações greco-romanas uma vez que, ao valorizarem as próprias regras de condutas, as pessoas passaram a se preocupar mais com os interesses individuais em detrimento dos coletivos, tornando-se cada vez mais independentes uns dos outros e mais devotados a si próprios; instaurando-se, assim, o que Foucault chamaria de cultura de si (Barbosa, Matos \& Costa, 2011).

\section{Encobrindo a Beleza: O Corpo como lugar de expiação e especulação científica}

Com o progredir dos tempos, as instituições greco-romanas evidenciadoras do culto e do cuidado com o corpo, tais como as termas, os esportes e o teatro; vão desaparecendo e dando abertura para o início de uma época de grande renúncia ao corpo: a Idade Média (Siqueira, 2011). Período histórico no qual, mais uma vez, o corpo aparece como elemento de consolidação das relações sociais, haja vista que as características agrárias presentes e imperantes no feudalismo justificavam o poder da constituição corporal na vida cotidiana, de modo que atributos como altura, cor da pele e peso corporal, refletiam para além do vínculo do indivíduo com a terra, suas funções e posição nessa sociedade (Barbosa, Matos \& Costa, 2011).

Nesse período, os discursos sobre o corpo são revestidos pela ideia de pecado, passa-se então a compreendê-lo como separado da alma, sendo um invólucro desta. Dessa maneira, a elevação espiritual passa a ter prioridade sobre os aspectos materiais, dando um novo significado a algumas práticas, como, por exemplo, a preocupação com uma alimentação regrada: para os gregos artifício de um corpo perfeito, e para o homem medieval renúncia aos prazeres materiais (Deus, Martins \& Santiago, 2013).

Essa cultura medieval do corpo, no sentido da desqualificação do humano, surge como contraponto ao sentimento trágico marcado pelo desamparo e pelo abandono dos deuses; de maneira que no corpo se materializa a obscuridade do pecado e da culpa sem a devida mediação do luto e o tempo de sublimação (Siqueira, 2011).

A repressão do homem medieval aparece como decorrente da existência da própria instituição religiosa a coibir qualquer manifestação criativa. $O$ cristianismo teria assim imprimido ao corpo as concepções de fé de um corpo crucificado e glorificado, comungado por todos os cristãos (Barbosa, Matos \& Costa, 2011).

Logo com o surgimento do cristianismo, a igreja atribuiu à eucaristia a metáfora do corpo Cristo, o "verbo se fez carne e habitou entre nós"; e o corpo de cada sujeito passa a ser visto como simbolismo divino de transcendência sobre a morte, sendo nomeado pelos evangelistas como templo de Deus e, portanto, não podendo ser ofuscado pelo pecado, nem desqualificado, uma vez que tinha sido redimido em Cristo. Essas são as primeiras tradições míticas das tradições bíblicas judaico-cristãs (Siqueira, 2011).

É importante salientar que foi a própria igreja a responsável por instituir práticas coercitivas sobre o corpo através do autoflagelo e do tribunal do Santo Ofício, o qual aplicava penas de castigos físicos e execuções públicas como alternativas à salvação das almas dos hereges. A tortura nas fogueiras, por exemplo, eram verdadeiros acontecimentos cerimoniais ou atos festivos sociais em torno da sentença do réu, a qual era assistida pela população e autoridades religiosas (Barbosa, Matos \& Costa, 2011).

A renúncia aos prazeres do corpo teve implicações e desdobramentos para uma demonização da mulher, com forte controle sobre sua sexualidade, desqualificação do trabalho manual, condenação à homossexualidade, censura ao riso, gesticulações, uso de máscaras e de maquiagem e na associação da gula à luxúria (Siqueira, 2011). Desse modo, mais uma vez, o corpo da mulher é representado de forma depreciativa na história, sendo responsabilizado por incitar o homem ao pecado, despertando-o aos desejos da carne através da sexualidade, entendimento este que passa a ser relacionado à prática da bruxaria.

Os "processos de bruxaria" eram centrados na ideia de que o demônio se apossava das almas das pessoas para lhes fazerem mal, entretanto essa possessão teria início via sexualidade pela dominação do corpo. Nesse sentido, as mulheres por descenderem de uma "costela" do homem eram, desde o princípio, impuras e por isso "agentes do demônio" ou feiticeiras. $\mathrm{Na}$ execução dos processos inquisicionais da conjuntura exposta, o corpo das bruxas toma destaque na cena, a começar pelo seu despimento, seguido da raspagem dos seus cabelos e pelos, concluindo com um minucioso exame à procura de algum sinal comprobatório e/ou delator de tais práticas (Barbosa, Matos \& Costa, 2011).

Outra característica marcante dessa sociedade foram as grandes epidemias, tais como a "peste negra", a tuberculose e a lepra, responsáveis por assolarem a Europa medieval em decorrência das precárias condições de higiene dos burgos, aldeias, casas e hábitos pessoais. Tais circunstâncias contribuíram para que mesmo o Estado feudal, estruturado entre Reis e Vassalos, fosse 
sensível às doenças e dores do corpo, tão repugnantes e tão presentes no cotidiano dos castelos e suas adjacências, colocando em xeque o saber da medicina escolástica, tendo esta se mostrado ineficaz no controle do flagelo, recorrendo aos barbeiros cirurgiões, até então rejeitados por ela (Siqueira, 2011).

Mesmo com o advento do Iluminismo no séc. XVIII, não foram observadas grandes mudanças nas concepções sobre o corpo, na verdade, é reafirmada a sua depreciação mediante o resgate dos conceitos do dualismo humano da antiguidade clássica e a dissociação dos dois elementos: corpo e alma, mais firmemente apregoados na Idade Média. A diferença substancial imprimida pelo Iluminismo é a subjugação do corpo à Racionalidade, na qual o homem deve ser compreendido como um ser moldável e passível de exploração, cujo corpo deve ser encarado em um plano inferior apenas como objeto de domínio e manipulação, e as experiências sensoriais devem ser descartadas (Barbosa, Matos \& Costa, 2011).

Essa manipulação do corpo vai ser bastante explorada através da arte, ainda que a área se desenvolvesse em decorrência da ciência, um exemplo disso são as pinturas de Leonardo Da Vinci expondo vísceras e corpos dissecados necessários ao estudo da anatomia, despontando nessa época ante o aprimoramento de procedimentos cirúrgicos.

No campo da estética, é possível notar ainda um padrão de beleza na conformação do ideal de corpo feminino dessa época pela incorporação e adequação das vestimentas, como, por exemplo, o uso de espartilhos por baixo dos longos vestidos, tal artifício conferia um acentuamento da silhueta pela diminuição da cintura em favor da exposição do decote e do quadril (Siqueira, 2011). Artifícios esses que materializavam as ambivalências projetadas sobre o corpo feminino: esconder ou evidenciar?

\section{Reinventando a Beleza: como a mídia pauta novas exigências de construção da imagem corporal}

A partir do século XX, a concepção de corpo vem acompanhada de uma notória medicalização que perdura até a nossa sociedade contemporânea; isso decorre do fato de a medicina ocidental ter catalogado os mais variados fatos ordinários da vida, ultrapassando ao que anteriormente fora imaginável, servindo, hoje, não apenas como o principal recurso nos casos de doença, mas como um guia de vida concorrente das tradicionais direções de consciência. É sob o discurso do progresso de seus conhecimentos sobre o funcionamento dos organismos, somado à supremacia do controle sobre as enfermidades, atestada pelo aumento da longevidade, que a medicina vem normatizando comportamentos, censurando prazeres e aprisionando o cotidiano em uma série de prescrições (Moulin, 2009).

Nessa sociedade contemporânea vigora uma sedução narcísica de verdadeira perseguição pela satisfação com a aparência corporal. Em um aspecto geral, as pessoas têm se dedicado com afinco a buscar um ideal de beleza impossível de ser atingido ou até mesmo perigoso para a própria saúde. Isso aparece como uma consequência do capitalismo que tem mercantilizado a beleza por meio da mídia, alimentando o consumismo desde o mais simples cosmético até aos mais refinados tratamentos oferecidos pela medicina estética; vendendo em propagandas para além dos produtos, a padronização de uma imagem do corpo, tanto masculina quanto feminina, a ser imitada e admirada por todos (Siqueira, 2011).

É curioso perceber que mesmo a beleza sendo um conceito tão abstrato, ao nos amarrarmos a estereótipos padronizados como acontece nas revistas femininas, modelos de um mesmo biótipo são apresentadas em situações corriqueiras usando vestidos de padrões repetitivos; ou seja, trajes destinados a mulheres altas, magras, esguias e planas, que diferem do biótipo brasileiro comum, de pessoas do sexo feminino medianas, com a valorização de curvas e medidas (Heinzelmann \& Strey, 2009).

Assim como as mulheres, os homens também são estimulados à valorização da beleza e da juventude, sendo cada vez maior a busca desenfreada por produtos de estética para exaltação da aparência. Nas classes mais abastadas, como A e B, os representantes do sexo masculino não economizam em esbanjar a sofisticação e a modernização do visual, como pré-requisito à autoconfiança para o sucesso na vida pessoal e profissional, tais exigências são feitas também pelo mercado de trabalho ao exigir uma boa apresentação; bem como pelas mulheres que passam a cobrar deles a mesma investidura que elas fazem na aparência corporal (Ghilardi-Lucena, 2011).

As possibilidades de correção e reconstrução do arcabouço corporal apontam para a negação da sua constituição primordial; o indivíduo tem procurado no corpo verdades sobre si as quais a sociedade não consegue responder. Em um contexto sócio-histórico instável e de rápidas mudanças, no qual impera a fragilidade das instituições influenciadoras da identidade, tais como família, religião, política e trabalho; as pessoas têm se apropriado cada vez mais do corpo como uma forma de expressão do próprio eu. A partir disso é disseminada uma cultura 
de valorização da beleza corporal, vendida como modelo de normalidade e que, portanto, requer um conjunto de práticas para ser mantida (Barbosa, Matos \& Costa, 2011).

\section{A Satisfação com Imagem Corporal como preditor de Saúde}

Os primeiros estudos sistematizados para conceituação do termo "Imagem Corporal" foram atribuídos a Schilder(1994), em sua obra A Imagem do Corpo, publicada em 1935, na qual partindo de uma união entre as concepções de integração somatopsíquica aos princípios de entendimento da postura corporal e a ideia psicodinâmica de que a pessoa é, antes de tudo, um "eu corporal"; propôs que a imagem corporal deve ser entendida enquanto três dimensões relacionais do homem: consigo mesmo, com os outros e com o mundo ao seu redor. Desse modo, todos teriam variadas imagens corporais multáveis ao longo da vida, inclusive quando o indivíduo vivencia algum transtorno mental.

Portanto, a imagem corporal é definida como um conjunto de imagens ou representações mentais que o sujeito elabora sobre o seu corpo ao longo da vida. Cabe ressaltar que a compreensão do corpo nesse sentido, transcende os aspectos do seu arcabouço para alcançar uma integração entre múltiplas dimensões que formarão o seu caráter singular representacional. Daí que a construção de sua imagem se dê paralelamente a estruturação e diferenciação do ego nos indivíduos (Sousa,2007).

A imagem corporal é um importante elemento imbricado na constituição da identidade pessoal em toda sua complexidade, em virtude de ser constituída a partir da própria idealização, junto à apreensão que se possa fazer sobre a percepção dos outros, além de como a pessoa objetivamente se vê. De tal modo, a satisfação do indivíduo consigo mesmo perpassa também por uma questão do aprimoramento de sua imagem, para se chegar àquela que ele deseja ter (Pitanguy \& Salgado, 2010).

Buscando analisar como essa questão é discutida nas publicações produzidas entre o período de janeiro de 2010 a dezembro de 2014, realizou-se um levantamento integrado na Biblioteca Virtual de Saúde - BVS, cruzando os descritores "Imagem Corporal" e "Satisfação Pessoal", delimitando os resultados para artigos completos, disponíveis nas bases Literatura Latino-Americana e do Caribe em Ciências da Saúde (LILACS) e Medical Literature Analysis and Retrieval System Online (MEDLINE), nos idiomas inglês, espanhol e português. Foi possível resga$\operatorname{tar} 17$ artigos, os quais foram agrupados primariamente tomando por base os públicos-alvo, aqueles em que não é possível defini-los, agrupou-se por aproximações de temáticas discutidas. Esse processo resultou no seguinte arranjo dos trabalhos: Psicometria (02), Trabalho Teórico (01), os que envolviam públicos de Adolescentes (06) e Adultos (08).

Acerca dos trabalhos voltados à psicometria, o de Conti, Scagliusi, Queiroz, Hearst e Cordás (2010) objetivaram descrever o processo de adaptação transcultural da Tripartite Influence Scale - Escala de Influência dos Três Fatores, quais sejam família amigos e mídia, cumprindo, pois, seu fim, apresentando valores satisfatórios de consistência interna, apontando para necessidade de estudos posteriores para validação externa, equivalência de mensuração e reprodutibilidade. O estudo de Hirata e Pilati (2010) era mais ousado, propunha-se ao desenvolvimento e validação preliminar de uma Escala Situacional de Satisfação Corporal - ESSC. Esses autores consideram que o entendimento da satisfação individual com o próprio corpo passa pela compreensão de como determinados fenômenos terão impacto na esfera individual e coletiva. No desenvolvimento do instrumento foram previstos, inicialmente, 28 itens, dos quais 24 foram adaptados de outra escala e os outros 04 restantes foram propostos durante os grupos de validação semântica. A Escala se mostrou válida, apresentando uma estrutura em quatro fatores, os quais variam conforme características sociodemográficas da amostra.

No trabalho teórico, Silva e Carminha (2012) colocam que a percepção da imagem corporal é influenciada por fatores biopsicossociais e, portanto, o processo de envelhecimento teria impactos significativos para a elaboração dessa imagem. Sendo assim, os teóricos realizaram uma revisão sistemática abrangendo um corte temporal de dez anos das publicações na temática sobre a avaliação de tal imagem em idosos e confirmaram uma carência de dados para embasar tal relação, além de uma distribuição geográfica restrita das produções, necessidade de busca de instrumentos mais adaptados e validados para essa população específica, reconhecendo tratar-se de um tema bastante complexo.

Ao adentrar nas publicações voltadas ao público adolescente, percebe-se uma predominância de estudos com amostras constituídas por escolares, objetivando, de maneira geral, investigar a prevalência de insatisfação com a imagem corporal. Nas discussões a respeito da temática, os autores são concordantes em apontá-la como uma possível relação causal bidirecional com os distúrbios alimentares (Andrade, Amaral \& Ferreira, 2010; Santana, Silva, Assis, Raich, Machado, Pinto, Moraes \& Ribeiro 
Junior, 2013; Finato, Rech, Migon, Gavineski, Toni \& Halpern, 2013).

A adolescência é um período no qual se evidencia uma maior busca pelo padrão estético, sendo, dessa maneira, da maior importância a investigação de sua repercussão sobre o corpo dos adolescentes, por se tratar de uma fase em que o indivíduo está muito suscetível às influências do meio. Neste estudo, é perceptível que as variáveis como sexo e tipo de escola tiveram maior influência sobre a insatisfação corporal do que a prática de atividade física. Nesse sentido, essa percepção decorre da pressão social a qual as meninas estão sujeitas com relação a seus próprios corpos, mas, sobretudo à "epidemia da beleza", a qual parece ser mais exigente com jovens, em especial adolescentes do sexo feminino, de classes mais abastadas. Já com relação ao tipo de escola, esse fator também é um reflexo dos valores das classes sociais e do meio cultural vivenciado (Andrade, Amaral \& Ferreira, 2010).

Outro fator relacionado à insatisfação com a imagem corporal, o espaço geográfico. Por exemplo, a cidade de Salvador - BA, onde os pesquisadores desenvolveram a pesquisa, tem um clima majoritariamente quente ao longo do ano e a via costeira inteira banhada por praias; essas condições encorajaram uma grande quantidade de pessoas a vestirem roupas leves e expor seus corpos, usando vestimentas como shorts e biquínis, ao mesmo tempo em que são geradas grandes preocupações com a aparência física (Santana, et al, 2013).

Desse modo, os mesmos autores, ao considerar a associação existente entre a insatisfação com a imagem corporal e as desordens que comprometem a saúde dos adolescentes, buscaram identificar a prevalência dessa insatisfação, bem como avaliar seus fatores associados em alunos da rede pública de ensino da cidade de Salvador. Nos estudos, os pesquisadores encontraram uma alta prevalência para tal público: incidência geral de 19,5\%, prevalência em meninas de $26,6 \%$, e em meninos de $10 \%$, apontando como fatores potenciais disso o excesso de peso ou obesidade, a magreza, a autopercepção de ser gordo e hábitos alimentares negativos, os quais merecem atenção especial, principalmente na promoção da saúde desse grupo, atentando para as suas peculiaridades, envolvendo a escola e a família no auxílio para que esses adolescentes desenvolvam suas imagens corporais sem distorções.

O trabalho de Finato et al (2013), mesmo não estabelecendo relação causal, reafirma que ser do sexo feminino e ter excesso de peso são fatores associados à insatisfação com a imagem corporal, como demonstrados respectivamente por Andrade, Amaral e Ferreira (2010) e Santana et al (2013).

Os demais trabalhos realizados com adolescentes abordam temas outros como satisfação corporal associada à prática de atividades físicas (Matias, Rolim, Kretzer, Schmoelz \& Andrade, 2010), anorexia nervosa (Husmeyer, Marcon, Santana \& Kállas, 2011) e Bullying (Rech, Halpern, Tedesco \& Santos, 2013).

Matias, Rolim, Kretzer, Schmoelz e Andrade (2010) demonstraram que as meninas são significativamente mais insatisfeitas com os seus corpos do que os meninos, além do fato de a variável da atividade física estar associada com o padrão de satisfação corporal, no qual os adolescentes mais ativos se mostraram mais satisfeitos e os mais sedentários mais insatisfeitos. Do que se pode afirmar, o valor de tal prática como mediadora na formação de conceitos sobre corporalidades traz benefícios à saúde psicológica desse público, especialmente no tocante aos aspectos da autoestima e bem-estar psicológico.

A pesquisa de Husmeyer, Marcon, Santana e Kállas (2011) encontrou uma alta prevalência de sintomas de anorexia nervosa e insatisfação com a imagem corporal na amostra das adolescentes estudadas; sendo estimada uma probabilidade de 2,56 maior de desenvolvimento dos sintomas entre os insatisfeitos. Todavia tais autores salientam a origem multifatorial do referido transtorno alimentar, apontando para a necessidade da realização de novas pesquisas com o mesmo público, mas envolvendo novas variáveis tais como: fatores psicológicos, socioculturais e genéticos, que possam estar relacionadas ao seu aparecimento.

No estudo de Rech, Halpern, Tedesco e Santos (2013), o Bullying aparece como variável independente e a insatisfação com a imagem corporal como variável dependente, assim, verificou-se que os adolescentes mais insatisfeitos com sua imagem corporal eram três vezes mais propensos a sofrerem a violência e quase duas vezes mais tendentes a praticarem; bem como o sedentarismo também evidenciou uma taxa $55 \%$ de sua inclinação ao exercício de vítima e o dobro dessa estimativa para o comportamento de agressor, com prevalência para adolescentes do sexo masculino.

No tocante aos estudos sobre imagem corporal realizados com o público adulto, estes enfatizaram tanto a satisfação (Cardosos, Sacomori, Sperandio \& Krüger, 2012) quanto a insatisfação (Costa, Santos, Modesto, Benute, Lôbo \& Lucia, 2010; Silva, Nahas, Sousa, Duca \& Peres, 2011); bem como, a análise dos aspectos relacionados às desordens alimentares (Costa, Vasconcelos \& Peres, 2010; 
Goltz, Stenzel \& Schneider, 2013). Além de abordarem relações de gênero a partir de variáveis como atividade física (Corbet, Campana \& Tavares, 2013) e aceitação de cirurgia plástica (Neves, Campana, Ferreira \& Tavares, 2012) . E por fim, um artigo relaciona o peso com índice de massa corporal-IMC (Simas, Macara \& Melo, 2014).

$\mathrm{Na}$ pesquisa que objetivou avaliar a satisfação corporal de estudantes de educação física, e a partir disso propor um questionário breve capaz de mensurá-la, Cardosos, Sacomori, Sperandio e Krüger (2012) encontraram diferenças relacionadas ao sexo, por exemplo, para os homens predominaram maiores médias entre as variáveis "o quanto gosta da cor de sua pele", "o quanto acha seu corpo proporcional" e "o quanto está satisfeito com seu corpo"; já para as mulheres as maiores médias foram obtidas em "o quanto olha seu corpo inteiro no espelho", "o quanto se auto massageia", "o quanto toca o corpo de forma geral", "o quanto percebe que os outros o acham sexy" e "o quanto gostaria de ser mais magra".

No que concerne à insatisfação, o trabalho realizado por Costa et al (2010), com uma amostra de universitários de dois estados do nordeste, mostrou que a maioria (58\%) concordava que a aparência ajudava na hora de conseguir um emprego, talvez por isso estivesse disposta (51\%) a mudá-la, uma vez que grande parte (64\%) almejava sua melhoria, estando apenas uma pequena parcela $(21 \%)$ satisfeita com o próprio peso, sendo que outros revelaram ainda estarem atualmente em uso de estratégias de emagrecimento, tanto através de dietas $(11 \%)$ quanto pela indução de vômitos $(7 \%)$.

Buscando determinar associações nesse sentido, Silva, Nahas, Sousa, Duca e Peres (2011), realizaram um estudo de base populacional em Florianópolis, Brasil, adotando como variáveis independentes os fatores sociodemográficos, comportamentos de saúde e morbidade; e encontraram um maior percentual de homens com baixa e mulheres com alta insatisfação, esses dados estiveram associados à presença de transtorno mentais e menores IMCs no primeiro grupo; e idade avançada, maiores IMCs e convivência com um companheiro no segundo. Não obstante, de maneira geral, os fatores como idade avançada, abuso de álcool, sedentarismo e obesidade foram implicados a altos índices de insatisfação em ambos os sexos.

Sobre a problemática dos transtornos alimentares, no estudo de Costa, Vasconcelos e Peres (2010), buscou-se avaliar seus fatores biopsicossociais em estudantes do sexo feminino, em uma universidade de Florianópolis, Brasil, verificou-se, ainda, que a insatisfação com a imagem corporal manteve associação independente com atitudes alimentares anormais, indicando a ocorrência de sintomas de anorexia nervosa.

A pesquisa de Goltz, Stenzel e Schneider (2013), realizada apenas com atletas do sexo masculino e objetivando identificar os comportamentos indicativos de tal desordem e a insatisfação com a imagem corporal, bem como sua relação com a gordura corporal; concluiu-se que cerca de um quarto desses atletas apresentaram comportamentos de transtornos alimentares, associados com a imagem corporal. Dentre aqueles participantes com maior percentual de gordura corporal, foi verificada maior predisposição à insatisfação com a própria imagem; não havendo, contudo, diferenças no comportamento alimentar e imagem corporal entre os praticantes de diferentes categorias de esportes.

Corbett, Campana e Tavares (2013) reafirmam as influências do meio social, no tocante ao olhar do outro e à cultura na qual o sujeito está inserido, para a construção de uma identidade corporal. Assim, buscando ampliar a compreensão acerca da satisfação corporal e sua idealização, tendo por base a atividade física, o IMC e o papel de gênero; os referidos autores realizaram uma investigação com um grupo de mulheres jovens, tanto sedentárias quanto praticantes de exercícios físicos; mas não encontraram quaisquer diferenças naquelas variáveis entre os dois grupos, diante disso é permitido supor que a adesão a exercícios pode ter outras motivações além daquelas relativas às mudanças na aparência, e mesmo que tal prática não altere significativamente o biótipo das mulheres, isso não contrapõe a visão cultural instituída acerca do corpo feminino.

Nesse sentido, a conclusão do trabalho de Neves, Campana, Ferreira \& Tavares (2012) é muito clarificadora ao evidenciar que as mulheres estão mais predispostas a suportarem dor e correrem os riscos decorrentes das cirurgias plásticas em comparação aos homens; ainda que para ambos os sexos se tenha encontrado correlações significativas entre as variáveis: aceitação da cirurgia, apreciação corporal e internalização da mídia. Esse meio de comunicação e difusão da informação, por ser considerado um veículo formador de opinião no tocante aos ideais de beleza; os autores alertam para o seu redirecionamento de incentivo mais ao procedimento cirúrgico do que aos outros fatores psicossociais, tais como satisfação com a vida e percepção de segurança financeira.

E, por fim, a pesquisa de Simas, Macara e Melo (2014), direcionada às especificidades e exigências dos cuidados que os bailarinos têm com o próprio corpo, buscou investigar se eles estavam satisfeitos com sua ima- 
gem produzida e se ela se relacionava com sua percepção do peso e seu IMC. Foi possível observar que, embora todos os bailarinos da pesquisa estivessem com seus IMCs dentro da faixa de normalidade, houve diferenças estatisticamente significativas, ainda que correlação baixa, envolvendo as três variáveis estudadas a partir do tipo de técnica de dança; por exemplo, os Clássicos se mostraram mais insatisfeitos por excesso de peso, desejando a redução deste; e os Contemporâneos apresentaram maior satisfação e anseio por pesar mais.

Diante do exposto, os estudos atuais reafirmam a complexidade multifatorial da Imagem Corporal enquanto um constructo, sendo bastante semelhante às motivações de adolescentes e adultos a se sentirem satisfeitos ou não com suas imagens construídas, as quais quando rejeitadas poderão desencadear quadros psicopatológicos, endossando a onda medicalizante atual do corpo.

\section{Considerações finais}

A beleza, de fato, tem sido uma das grandes ocupações e preocupações do homem ao longo dos tempos, as concepções responsáveis por caracterizá-la variaram também nessa escala temporal, entre culturas e contextos sociais. Não se constata, entretanto, esforços no intento de defini-la, em vistas desta dificuldade vê-se que a beleza aparece sempre como um aspecto e/ou dimensão associada à construção da imagem corporal, imprimindo-lhe atributos de uma perfeição quase divinal, daquilo que é bonito e bom, mas também relativa já que os homens, mesmo sendo mortais, são incentivados a persegui-la e atingi-la.

Abstrai-se que, se ao homem é permitido atingir essa beleza é porque ela pode ser mensurada, padronizada e/ ou estereotipada. Então, a cada época, o grupo social com mais capacidade de influenciar o modo de pensar das pessoas, é responsável por determinar um modelo de constituição de imagem corporal considerada bela, o qual será imposto e rapidamente absorvido pelos demais grupos sociais.

Observou-se, ainda, que a integração entre a beleza e a imagem corporal é mantida pela expressão da sexualidade, pois nas primeiras civilizações as formas de exposição dos corpos, as mais diferentes atividades humanas eram vistas como uma aproximação e exaltação da beleza dos deuses. Com o avigoramento do monoteísmo, em nome de um único Deus, passa-se a associar o culto à beleza da forma física ao exercício do pecado e ao despertar das paixões humanas. Assim, a sexualidade passa a ser reprimida e a beleza da imagem corporal escondida. Somente quando ocorre a separação dos papéis entre religião e Estado como instituições regulamentadoras das relações sociais é que outras ganharam notoriedade nesse embate para determinação de novos paradigmas do monopólio do pensamento social. Uma das mais importantes instituições é a medicina, despontando enquanto ramo da ciência que, ao resgatar a sexualidade entre o binômio beleza-corpo, a partir da produção de um discurso sobre saúde e bem-estar, coloca em evidência o atributo da sensualidade.

Todavia mesmo o discurso da medicina não se mostrou suficiente para perdurar hegemônico na sociedade contemporânea, sobretudo porque a defesa do modelo de corpo biomédico revelou uma faceta excludente de um grande contingente de pessoas que não conseguiram atingir tal padrão beleza, como apontam os estudos no Brasil. Ao contrário disso, o belo acabou produzindo um contrassenso do que se pode ser aceito nessa sociedade, elegendo a sensualidade como atributos de poucos, gerando estigmas sociais com repercussão no aumento de pessoas com sofrimento psíquico.

Essa sensação de mal-estar promoveu um ambiente propício à eclosão de movimentos contra-hegemônicos, pois começou-se a questionar o real poder das instituições influenciadoras desse pensamento social. No entanto parece que nesse cenário os indivíduos tendem a seguir o movimento da corrente que lhes sejam mais convenientes, principalmente no Brasil. Se por um lado surgem organizações dispostas a defender os excluídos do padrão, ressignificando um novo conceito e perfis de beleza, os sujeitos que possivelmente se beneficiariam delas não se engajaram na luta social e tampouco na conscientização política-pessoal, continuam, assim, a perseguir o padrão. Donde nos faz refletir e questionar: Como as instituições formadoras de opinião surgem, resistem/perduram e se alternam ou são substituídas a cada período de tempo?

\section{Referências}

Andrade, M. R.M., Amaral, A. C. S. \& Ferreira, M. E. C. (2010). A cultura do corpo ideal: prevalência de insatisfação corporal entre adolescentes. Psicologia em Pesquisa, UFJF, 40(1), 24-30. Recuperado de: http://pepsic.bvsalud.org/ scielo.php? script=sci_arttext\&pid=S1982-12472010000100004.

Barbosa, M. R., Matos, P. M. \& Costa M. E. (2011). Um olhar sobre o corpo: o corpo ontem e hoje. Psicologia \& Sociedade, 23 (1), 24-34. Recuperado de: http://www.scielo.br/pdf/psoc/v23n1/a04v23n1.pdf.

Cardosos, F. L., Sacomori C., Sperandio, F. F. \& Krüger, A. P. ( 2012). Satisfação corporal em acadêmicos de Educação Física: proposta de um questionário. Motriz: rev. educ. fis., 18(1), 63-71. Recuperado de: http:// www.scielo.br/pdf/motriz/v18n1/v18n1a07.pdf.

Cassimiro, E. S., Galdino, F. F. L. \& Sá, G. M. (2012). As concepções de corpo construídas ao longo da história ocidental: da Grécia antiga à contempo-

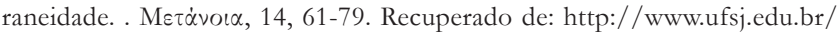
portal2-repositorio/File/revistalable/4_GERALDO_CONFERIDO.pdf.

Conti, M. A., Scagliusi, F., Queiroz, G. K. O., Hearst, N. \& Cordás, T. A. (2010). Adaptação transcultural: tradução e validação de conteúdo para o 


\section{A CONSTRUÇÃO SOCIAL DO CORPO: COMO A PERSEGUIÇÃO DO IDEAL DO BELO INFLUENCIOU AS CONCEPÇÕES DE SAÚDE NA SOCIEDADE BRASILEIRA CONTEMPORÂNEA}

idioma português do modelo da Tripartite Influence Scale de insatisfação corporal. Cad. Saúde Pública, 26(3), 503-513. Recuperado de: http://www. scielo.br/pdf/csp/v26n3/08.pdf.

Corbet, C. A., Campana, A. N. N. B. \& Tavares, M. C. G. C. F. (2013). Atividade física, gênero e imagem corporal. SALUSVITA, 32(3), 307-320. Recuperado de: http://www.usc.br/biblioteca/salusvita/salusvita_v32_ n3_2013_art_07.pdf.

Costa, K. C. B. C., Santos, N. O., Modesto, S. E. F., Benute, G. R. G., Lôbo, R. C. M. M. \& Lucia, M. C. S. (2010). Insatisfação corporal em estudantes universitários da área de saúde nos Estados de Alagoas e Sergipe. Mudanças - Psicologia da Saúde, 18(1-2), 1-6. Recuperado de: https://www.metodista. $\mathrm{br} /$ revistas/revistas-metodista/index.php/MUD/article/view/1877/2410.

Costa, L. C. F., Vasconcelos, F. A. G. \& Peres, K. G. (2010). Influence of Biological, Social and Psychological Factors on Abnormal Eating Attitudes among Female University Students in Brazil. J. HEALTH POPUL. NUTR., 28(2), 173-181. Recuperado de: http://www.ncbi.nlm.nih.gov/ $\mathrm{pmc} /$ articles/PMC2980880/.

Deus, A., Martins, N. E. G. \& Santiago, L. V. (2013). As representações do corpo ao longo do tempo: seus discursos e suas construções. Anais do IX Congresso Nacional de Educação EDUCERE. Recuperado de: http://educere. bruc.com.br/ANAIS2013/pdf/8185_5087.pdf.

Finato, S., Rech, R. R., Migon, P., Gavineski, I. C., Toni, V. \& Halpern, R. (2013). Insatisfação com a imagem corporal em escolares do sexto ano da rede municipal de Caxias do Sul, no Rio Grande do Sul. Rev. Paul. Pediatr., 31(1), 65-70. Recuperado de: http://www.scielo.br/pdf/rpp/v31n1/11.pdf.

Ghilardi-Lucena, M. I. (2011). Gênero e representações sociais na mídia: o corpo masculino. REDISCO, 1(1), 88-97. Recuperado de: http://periodicos. uesb.br/index.php/redisco/article/viewFile/900/819.

Goltz, F. R., Stenzel, L. M. \& Schneider, C. D. (2013). Disordered eating behaviors and body image in male athletes. Revista Brasileira de Psiquiatria, 35, 237-242. Recuperado de: http://www.scielo.br/pdf/rbp/v35n3/15164446-rbp-2013-35-3-237.pdf.

Heinzelmann, F. L. \& Strey, M. (2009). A mulher e a beleza: representações femininas na revista Vogue. IV Mostra de Pesquisa da Pós-Graduação PUCRS. Recuperado de: http://www.pucrs.br/edipucrs/IVmostra/IV_MOSTRA_ PDF/Psicologia/72145-FERNANDA_LYRIO_HEINZELMANN.pdf.

Hirata, E. \& Pilati, R. (2010). Desenvolvimento e validação preliminar da Escala Situacional de Satisfação Corporal - ESSC. Psico-USF, 15(1), 1-11. Recuperado de: http://www.scielo.br/pdf/pusf/v15n1/02.pdf

Husmeyer, A. R., Marcon, S. S., Santana, R. G. \& Kállas, D. (2011). A anorexia nervosa e os fatores associados em adolescentes do sexo feminino em município do sul do Brasil. Archivos Latinoamericanos de Nutrición, 61(3), 262269. Recuperado de: http://www.scielo.org.ve/pdf/alan/v61n3/art05.pdf.

Matias, T. S., Rolim, M. K. S. B., Kretzer, F. L., Schmoelz, C. P. \& Andrade, A. (2010). Satisfação corporal associada a prática de atividade física na adolescência. Motriz, 16(2), 370-378. Recuperado de: http://www. periodicos.rc.biblioteca.unesp.br/index.php/motriz/article/view/1980$-6574.2010 \mathrm{v} 16 \mathrm{n} 2 \mathrm{p} 370 / 2982$.

Moulin, A. M. (2009). O corpo diante da medicina. In Corbin A, Courtine J, Vigarello G (Orgs.). História do corpo: as mutações do olhar. O século XX. v. 3, 3 ed. Petrópolis, RJ: Vozes, pp 15-82.
Neves, A. N., Campana, B., Ferreira, L. \& Tavares, M. C. G. C. M. (2012). Associações e diferenças entre homens e mulheres na aceitação de cirurgia plástica estética no Brasil. Rev. Bras. Cir. Plást., 27(1), 108-14. Recuperado de: http://www.scielo.br/pdf/rbcp/v27n1/18.pdf.

Pitanguy, I. \& Salgado, F. (2010). Aspectos Filosóficos e Psicossociais da Cirurgia Plástica. In: Melo Filho J, Burd. M. e cols. Psicossomática Hoje. 2 ed. Porto Alegre: Artmed, p. 356-367.

Rech, R. R., Halpern, R., Tedesco, A. \& Santos, D. F. (2013). Prevalence and characteristics of victims and perpetrators of bullying. J Pediatr., 89(2), 164-170. Recuperado de: http://ac.els-cdn.com/S0021755713000235/1s2.0-S0021755713000235-main.pdf?_tid=cb02b61e-edc0-11e4-afac-00000aa cb360\&acdnat $=1430237482 \_705 \mathrm{dd} 2 \mathrm{ed} 8 \mathrm{bfeec} 1 \mathrm{af0} 0 \mathrm{c} 26 \mathrm{fe} 68 \mathrm{c} 6730 \mathrm{ea}$.

Rodrigues, N. S. (2011). A nudez do guerreiro grego. Humanitas, 63, 201-216. Recuperado de: http://www.uc.pt/fluc/eclassicos/publicacoes/ficheiros/ humanitas63/11_NSR.pdf.

Rother, E. T. (2007). Revisão sistemática X revisão narrativa. Acta Paulisto de Enfermagem, 20(2), v-vi. Recuperado de: https://dx.doi.org/10.1590/ S0103-21002007000200001

Santana, M. L. P., Silva, R. C. R., Assis, A. M. O., Raich, R. M., Machado, M. E. P. C., Moraes, L. T. L. P. \& Ribeiro Junior, H. C. (2013). Factors associated with body image dissatisfaction among adolescents in public schools students in Salvador, Brazil. Nutrición Hospitalaria, 28(3), 747-755. Recuperado de: http://www.nutricionhospitalaria.com/pdf/6281.pdf.

Schider, P. (1994). A Imagem do Corpo: as energias construtivas da psique. R Wertman (trad.). São Paulo: Martins Fontes.

Silva, D. A. S., Nahas, M. V., Sousa, T. F., Duca, G. F. D. \& Peres, K. G. (2011). Prevalence and associated factors with body image dissatisfaction among adults in southern Brazil: A population-based study. Body Image, 8(4), 427- 431.

Silva, G. M. L. \& Carminha, I. O. (2012). Avaliação da imagem corporal de idosos brasileiros: uma revisão sistemática. Estud. interdiscipl. envelhec., 17(2), 233-249. Recuperado de: http://seer.ufrgs.br/index.php/RevEnvelhecer/ article/view/24287/25398.

Simas, J. P. N., Macara, A. \& Melo, S. I. L. (2014). Imagem corporal e sua relação com peso e índice de massa corporal em bailarinos profissionais. Rev. Bras. Med. Esporte, 20(6), 433-7. Recuperado de: http://www.scielo.br/ pdf/rbme/v20n6/1517-8692-rbme-20-06-00433.pdf.

Siqueira, A. J. (2011). As representações do corpo na idade média. Vivência, 33, 49-58. Recuperado de: http://www.cchla.ufrn.br/Vivencia/sumarios/37/ PDF\%20para\%20INTERNET_37/03_Ant\%C3\%B4nio\%20Jorge $\% 20$ Siqueira.pdf.

Sousa, M. S. F. (2007). A busca pela cirurgia plástica estética: um sintoma da sociedade contemporânea? Tese de doutorado, Pontifícia Universidade Católica de São Paulo, São Paulo, SP.

Submetido em: 3-12-2018

Aceito em: 18-7-2019 